Acta Crystallographica Section B

Structural

Science

ISSN 0108-7681

John. A. Cowan, ${ }^{a, b_{*}}$ Judith A. K.

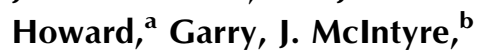
Samuel M.-F Lo ${ }^{c}$ and Ian D. Williams $^{\mathrm{c}}$

anstitut Laue Langevin, 6 Rue Jules Horowitz, BP156, 38042 Grenoble, CEDEX 9, France,

${ }^{\mathbf{b}}$ Department of Chemistry, University of Durham, Durham DH1 3LE, England, and ${ }^{\mathbf{c}}$ Department of Chemistry, Hong Kong University of Science and Technology, Clear Water Bay, Hong Kong, People's Republic of China

‡ Correspondence address: SRS Daresbury Laboratory, Daresbury, Cheshire WS4 4AD, England.

Correspondence e-mail: j.a.cowan@dl.ac.uk

\title{
Variable-temperature neutron diffraction studies of the short, strong hydrogen bonds in the crystal structure of pyridine-3,5-dicarboxylic acid
}

Pyridine-3,5-dicarboxylic acid has been studied by singlecrystal neutron diffraction at 15 and $296 \mathrm{~K}$. Pyridine-3,5dicarboxylic acid, in which the carboxylic acid protons have been replaced by deuterons, has also been studied at 15, 150 and $296 \mathrm{~K}$. The protonated structure contains a short $\mathrm{N} \cdots \mathrm{H} \cdots \mathrm{O}$ hydrogen bond [N..O $2.523(2) \AA$ at $15 \mathrm{~K}]$. Temperature-dependent proton migration occurs where the $\mathrm{N}-\mathrm{H}$ distance in the hydrogen bond changes from 1.213 (4) $\AA$ at $15 \mathrm{~K}$ to 1.308 (6) $\AA$ at $300 \mathrm{~K}$. In the deuterated structure the overall hydrogen-bond length increased [N...O 2.538 (3) $\AA$ at $15 \mathrm{~K}$ ] and the magnitude of the migration increased so that the N-D distance changes from 1.151 (3) $\AA$ at $15 \mathrm{~K}$ to 1.457 (4) $\AA$ at $300 \mathrm{~K}$.

\section{Introduction}

Temperature-dependent proton migration has been observed recently in short, strong $\mathrm{N}$...O hydrogen bonds in the cocrystal of 4-methylpyridine and pentachlorophenol (Steiner et al., 2001) and the 1:2 co-crystal of benzene-1,2,4,5-tetracarboxylic acid and 4,4'-bipyridine (BTA-2BPY; Cowan et al., 2003). Both of these structures contain short, strong hydrogen bonds, with $\mathrm{N}$. . O distances of $c a 2.51 \AA$, in which the proton lies closer to the $\mathrm{O}$ atom at room temperature and migrates $c a$ $1 \AA$ across the hydrogen bond to lie closer to the $\mathrm{N}$ atom at $20 \mathrm{~K}$.

The Cambridge Structural Database (CSD; Allen, 2002) was searched for comparable short $\mathrm{N}-\mathrm{H} \cdots \mathrm{O} / \mathrm{O}-\mathrm{H} \cdots \mathrm{N}$ hydrogen bonds, in which proton migration might also occur. One of the shortest and straightest bonds, with the $\mathrm{H}$ atom found in the centre of the hydrogen bond, was in the crystal structure of pyridine-3,5-dicarboxylic acid [PDA, see (I)], with an N. . O separation of $2.515 \AA$ A, N-H distance of $1.289 \AA$ and $\mathrm{O}-\mathrm{H}$ distance of $1.230 \AA$ at room temperature (Takusagawa et al., 1973a; CSD refcode DINICA10). Not only are the hydrogen-bond parameters very similar to those in the cocrystal of BTA-2BPY, but also the constituents of the hydrogen bonds, a pyridyl group and a carboxylic acid group, are identical.<smiles></smiles>

Pyridine-2,3-dicarboxylic acid (quinolinic acid) contains a short intramolecular hydrogen bond (Takusagawa et al.,
Received 14 June 2005

Accepted 20 September 2005
(C) 2005 International Union of Crystallography Printed in Great Britain - all rights reserved 
Table 1

Data collection and refinement details.

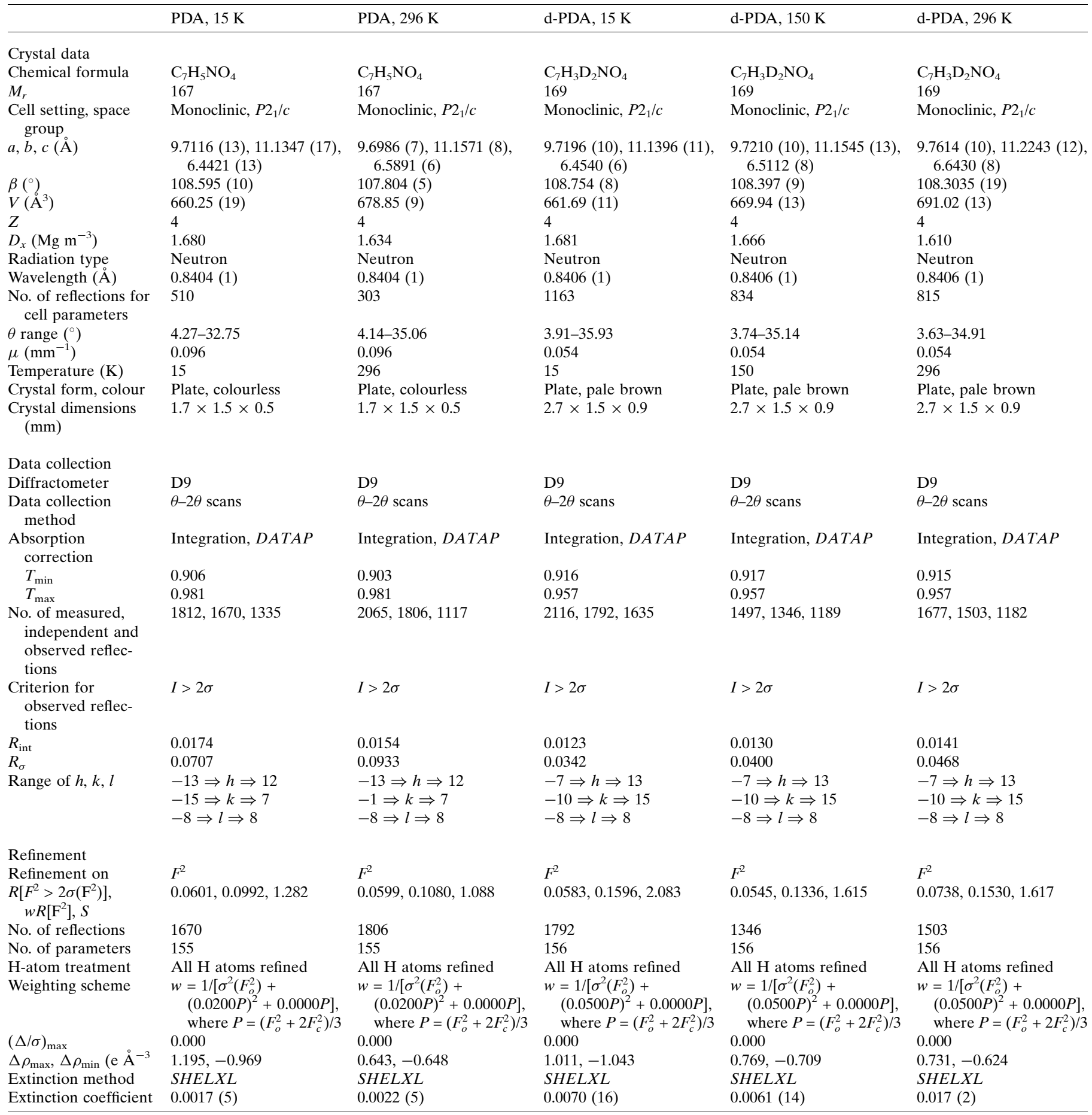

Computer programs used: MAD and HKLGEN (Barthelemy, 1984), RAFD9 (Filhol, 1998), RACER (Wilkinson et al., 1988), SHELXS97 (Sheldrick, 1990$),$ SHELXL97 (Sheldrick, 1997).

1973b) between a carboxylic acid and a carboxylate group. Neutron diffraction studies of the protonated (Takusagawa \& Koetzle, 1978) and the deuterated forms (Takusagawa \& Koetzle, 1979) show that upon deuteration the $\mathrm{O}-\mathrm{H}$ distance in the hydrogen bond increases by $c a 0.02 \AA$ and the $\mathrm{O} \cdots \mathrm{O}$ distance decreases marginally. The $\mathrm{O}-\mathrm{H}$ distance increases on lowering the temperature by $c a 0.01 \AA$ and the $\mathrm{O}-\mathrm{D}$ distance increases by $c a 0.004 \AA$. A very similar, but slightly larger, effect has been observed in lithium hydrogen phthalate monohydrate (Küppers et al., 1985), where the $\mathrm{H}$ atom moves 
by $c a 0.04 \AA$ and a D atom by $c a 0.03 \AA$ towards the centre of the hydrogen bond on lowering the temperature from 298 to $15 \mathrm{~K}$ ( $35 \mathrm{~K}$ for the deuterated structure).

On deuteration of a hydrogen bond the distance between the donor and acceptor atoms is often seen to increase (Robertson \& Ubbelohde, 1939), although often by an amount smaller than the standard uncertainties of the bond lengths (Sakhawat Hussain \& Schlemper, 1980). It is expected that the donor-acceptor distance should increase if the bond has a double-minimum potential well, and decrease for a singleminimum potential well (Singh \& Wood, 1969; Ichikawa, 1978). In some cases deuteration has a very strong effect: for example, in $\mathrm{KH}_{2} \mathrm{PO}_{4}$ the protonated structure has a tetragonal space group, but the fully deuterated structure has a monoclinic space group (Nelmes et al. 1982). Deuteration, therefore, does change the hydrogen-bond potential energy well, although often only by a small amount.

The expectation value of the $\mathrm{H}$-atom position in a hydrogen bond depends upon the shape of the potential-energy well. Deuterium is heavier than hydrogen and will lie at a lower energy in a potential-energy well, consequently, the difference in the deuterium and hydrogen positions will reveal details about the shape of the well.

\section{Experimental}

Crystals were formed in $\geq 80 \%$ yield by heating PDA in $1 \mathrm{~mL}$ of $\mathrm{H}_{2} \mathrm{O}$ for $2 \mathrm{~d}$ at $453 \mathrm{~K}$ in a $23 \mathrm{~mL}$ Teflon-lined Parr vessel under autogenous pressure. A typical crystal size was 1$2 \mathrm{~mm}^{3}$. Larger specimens up to $5 \mathrm{~mm}^{3}$ could be obtained by cyclic heating and cooling of the bombs between 273-453 K. Deuterated crystals (d-PDA) were obtained by recrystallizing PDA from $\mathrm{D}_{2} \mathrm{O}$ using the same technique. The procedure was repeated to ensure maximum deuteration.

Neutron diffraction data were collected on the D9 diffractometer at the Institut Laue Langevin (ILL). In the D9 experiment a crystal of volume $c a 1.5 \mathrm{~mm}^{3}$ was attached with epoxy glue to a vanadium pin, which was then mounted upon the Displex cryorefrigerator (Archer \& Lehmann, 1986) on the $\chi$ circle of D9. D9 was equipped with a small multiwire, proportional ${ }^{3} \mathrm{He}$-gas area detector, which for this experiment allowed optimum delineation of each reflection from the considerable background (owing mainly to the incoherent

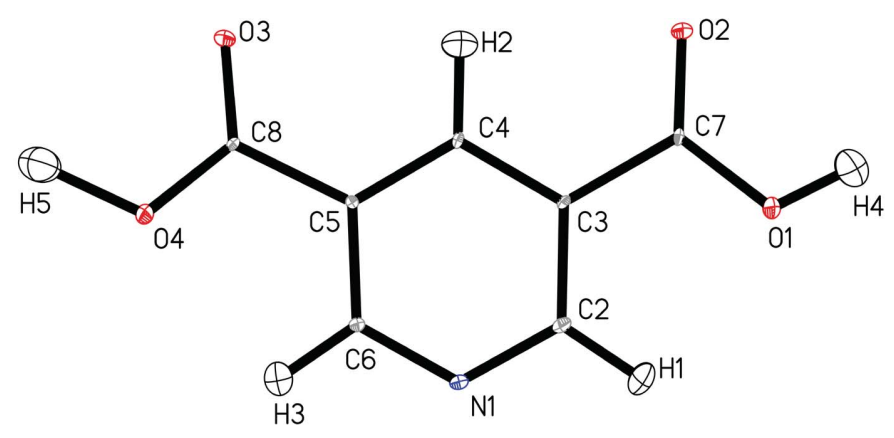

Figure 1

Displacement ellipsoid plot (50\%) of PDA from the $15 \mathrm{~K}$ data. scattering from hydrogen in the sample), and very precise determination of the lattice parameters since the centres of all reasonably strong reflections were observed. Diffraction data were collected at room temperature with a wavelength of 0.8404 (1) $\AA$ to $\theta=35^{\circ}$ from a $\mathrm{Cu}(220)$ monochromator. An Erbium filter was used to remove $\lambda / 2$ contamination. The $00 \overline{2}$ reflection was measured approximately every 50 reflections and showed no significant change during the data collection. Vanadium and aluminium heat shields were placed over the crystal, which was then cooled to $15 \mathrm{~K}$ and the data collection procedure repeated.

The cell dimensions were refined using the ILL program $R A F D 9$ and integrated intensities produced using the ILL program RACER (Wilkinson et al., 1988). The data were corrected for absorption in the crystal using the program DATAP (Coppens, 1979) and the low-temperature data were also corrected for absorption in the aluminium and vanadium cryorefrigerator vacuum and heat shields.

A pale brown crystal of d-PDA was mounted in the same way upon the D9 dffractometer. Data were collected at 15, 150 and $296 \mathrm{~K}$ in the same was as for PDA, except that the heat shields were also used during the room-temperature data collection to prevent any exchange of deuterium from the crystal with hydrogen from the atmosphere. During the data collection, a piece of extra crystal was identified and indexed. The intensity from the extra crystal was less than $10 \%$ of the intensity of the main crystal and as it affected only a few reflections it was ignored and the majority of the affected reflections were omitted from the refinement (although the resultant $R$ factors and goodness-of-fit were slightly higher than expected).

The initial structural model for the neutron refinements was taken from the original structure determination by Takusagawa et al. (1973a). The structures were refined using SHELX (Sheldrick, 1997) with full-matrix least-squares on $F^{2}$ using the neutron scattering lengths tabulated by Sears (1992). All atoms were refined with anisotropic displacement parameters. Molecular graphics were produced using SHELXTL/PC (Sheldrick, 1999). The data collection and refinement details are summarized in Table $1 .{ }^{\mathbf{1}}$

\section{Results and discussion}

\subsection{Structure review}

Pyridine-3,5-dicarboxylic acid (Fig. 1) crystallizes in the space group $P 2_{1} / c$ with four molecules in the unit cell. One strong $\mathrm{O}-\mathrm{H} \cdots \mathrm{O}$ bond and a strong $\mathrm{N}-\mathrm{H} \cdots \mathrm{O}$ bond are formed to link the molecules in infinite two-dimensional planar sheets perpendicular to the $c$ axis. All the parameters discussed were taken from the $15 \mathrm{~K}$ neutron diffraction data unless otherwise specified.

\footnotetext{
${ }^{1}$ Supplementary data for this paper, including difference Fourier maps calculated from the final refined structures and with H/D5 omitted, are available from the IUCr electronic archives (Reference: BS5020). Services for accessing these data are described at the back of the journal.
} 
Table 2

Hydrogen-bond geometry $\left(\AA,^{\circ}\right)$.

\begin{tabular}{|c|c|c|c|c|}
\hline & $D \cdots A(\AA)$ & $D-\mathrm{H}(\AA)$ & $\mathrm{H} \cdots A(\AA)$ & $D-\mathrm{H}-A\left(^{\circ}\right)$ \\
\hline \multicolumn{5}{|l|}{ PDA, $15 \mathrm{~K}$} \\
\hline $\mathrm{N} 1{ }^{\mathrm{i}}-\mathrm{H} 5 \cdots \mathrm{O} 4$ & $2.523(2)$ & $1.213(4)$ & $1.311(5)$ & $176.4(4)$ \\
\hline $\mathrm{O} 1-\mathrm{H} 4 \cdots \mathrm{O} 3^{\mathrm{ii}}$ & $2.569(3)$ & $1.025(4)$ & $1.558(4)$ & $167.7(4)$ \\
\hline $\mathrm{C} 2-\mathrm{H} 1 \cdots \mathrm{O} 2^{\mathrm{ii}}$ & 3.549 (3) & $1.094(4)$ & $2.499(4)$ & $160.6(3)$ \\
\hline $\mathrm{C} 4-\mathrm{H} 2 \cdots \mathrm{O} 1^{\mathrm{iii}}$ & 3.157 (3) & $1.088(4)$ & $2.181(4)$ & $148.0(3)$ \\
\hline $\mathrm{C} 6-\mathrm{H} 3 \cdots \mathrm{O} 3^{\mathrm{iv}}$ & $3.228(3)$ & $1.086(4)$ & $2.440(4)$ & $128.3(3)$ \\
\hline \multicolumn{5}{|l|}{ PDA, $296 \mathrm{~K}$} \\
\hline $\mathrm{N} 1^{\mathrm{i}}-\mathrm{H} 5 \cdots \mathrm{O} 4$ & $2.525(3)$ & $1.308(6)$ & $1.218(6)$ & $177.8(6)$ \\
\hline $\mathrm{O} 1-\mathrm{H} 4 \cdots \mathrm{O} 3^{\mathrm{ii}}$ & $2.591(3)$ & $1.004(5)$ & $1.608(5)$ & $165.0(5)$ \\
\hline $\mathrm{C} 2-\mathrm{H} 1 \cdots \mathrm{O} 2^{\mathrm{ii}}$ & 3.567 (3) & $1.078(4)$ & $2.530(5)$ & $161.1(3)$ \\
\hline $\mathrm{C} 4-\mathrm{H} 2 \cdots \mathrm{O} 1^{\mathrm{iii}}$ & 3.193 (3) & $1.083(5)$ & $2.205(5)$ & 150.7 (4) \\
\hline $\mathrm{C} 6-\mathrm{H} 3 \cdots \mathrm{O} 3^{\mathrm{iv}}$ & $3.242(3)$ & $1.092(4)$ & $2.457(5)$ & $127.8(3)$ \\
\hline \multicolumn{5}{|l|}{ d-PDA, $15 \mathrm{~K}$} \\
\hline $\mathrm{N} 1^{\mathrm{i}}-\mathrm{D} 5 \cdots \mathrm{O} 4$ & $2.538(3)$ & $1.151(3)$ & $1.389(3)$ & $175.8(3)$ \\
\hline $\mathrm{O} 1-\mathrm{D} 4 \cdots \mathrm{O} 3^{\mathrm{ii}}$ & $2.562(3)$ & $1.022(3)$ & $1.553(3)$ & $168.5(3)$ \\
\hline $\mathrm{C} 2-\mathrm{H} 1 \cdots \mathrm{O} 2^{\mathrm{ii}}$ & $3.561(3)$ & $1.105(11)$ & $2.496(11)$ & $161.6(8)$ \\
\hline $\mathrm{C} 4-\mathrm{H} 2 \cdots \mathrm{O} 1^{\mathrm{iii}}$ & $3.150(3)$ & $1.083(4)$ & $2.182(5)$ & $147.5(4)$ \\
\hline $\mathrm{C} 6-\mathrm{H} 3 \cdots \mathrm{O} 3^{\text {iv }}$ & $3.240(3)$ & 1.089 (13) & $2.450(12)$ & $128.4(8)$ \\
\hline \multicolumn{5}{|l|}{ d-PDA, $150 \mathrm{~K}$} \\
\hline $\mathrm{N} 1^{\mathrm{i}}-\mathrm{D} 5 \cdots \mathrm{O} 4$ & $2.531(3)$ & $1.192(3)$ & $1.340(4)$ & $176.3(4)$ \\
\hline $\mathrm{O} 1-\mathrm{D} 4 \cdots \mathrm{O} 3^{\mathrm{ii}}$ & $2.580(3)$ & $1.016(3)$ & $1.580(3)$ & $167.3(3)$ \\
\hline $\mathrm{C} 2-\mathrm{H} 1 \cdots \mathrm{O} 2^{\mathrm{ii}}$ & $3.566(3)$ & $1.076(10)$ & $2.535(11)$ & $160.0(10)$ \\
\hline $\mathrm{C} 4-\mathrm{H} 2 \cdots \mathrm{O} 1^{\mathrm{iii}}$ & 3.169 (3) & $1.085(4)$ & $2.194(5)$ & $148.2(4)$ \\
\hline $\mathrm{C} 6-\mathrm{H} 3 \cdots \mathrm{O} 3^{\mathrm{iv}}$ & $3.240(3)$ & 1.058 (11) & $2.473(11)$ & $128.5(8)$ \\
\hline \multicolumn{5}{|l|}{ d-PDA, 296 K } \\
\hline $\mathrm{N} 1^{\mathrm{i}}-\mathrm{D} 5 \cdots \mathrm{O} 4$ & $2.564(3)$ & $1.457(4)$ & $1.108(4)$ & $177.6(4)$ \\
\hline $\mathrm{O} 1-\mathrm{D} 4{ }^{\prime O O O} 3^{\mathrm{ii}}$ & $2.640(3)$ & $0.993(4)$ & $1.678(3)$ & $162.1(3)$ \\
\hline $\mathrm{C} 2-\mathrm{H} 1 \cdots \mathrm{O} 2^{\mathrm{ii}}$ & $3.579(3)$ & 1.087 (12) & $2.537(12)$ & $160.2(10)$ \\
\hline $\mathrm{C} 4-\mathrm{H} 2 \cdots \mathrm{O} 1^{\mathrm{iii}}$ & $3.240(3)$ & $1.092(5)$ & $2.242(6)$ & $150.9(4)$ \\
\hline $\mathrm{C} 6-\mathrm{H} 3 \cdots \mathrm{O} 3^{\mathrm{iv}}$ & $3.252(3)$ & $1.070(12)$ & $2.486(12)$ & 127.7 (10) \\
\hline
\end{tabular}

The internal geometry of the PDA molecule in the crystal conforms more closely to the zwitterionic form in which one carboxylic acid group has become deprotonated and the $\mathrm{N}$ atom has become protonated. This is similar to pyridine-2,3dicarboxylic acid (quinolinic acid; Takusagawa et al., 1973b) and pyridine-3,4-dicarboxylic acid (cinchomeric acid, Takusagawa et al., 1973c) which both crystallize in the zwitterionic form. The $\mathrm{C}-\mathrm{O}$ bond lengths in the carboxylic acid group $[\mathrm{C} 7(=\mathrm{O} 2)-\mathrm{O} 1-\mathrm{H} 4]$ of $\mathrm{C} 7-\mathrm{O} 1=1.319$ (2) $\AA$ and $\mathrm{C} 7=\mathrm{O} 2$ $=1.217$ (2) $\AA$ conform to the average values tabulated in International Tables for Crystallography (Allen et al., 1992) in which $\mathrm{C}=\mathrm{O}$ is 1.226 (20) $\AA$ and $\mathrm{C}-\mathrm{O}$ is 1.305 (20) $\AA$ for a carboxylic acid group attached to an aromatic ring. This carboxylic acid group donates one strong hydrogen bond from $\mathrm{O} 1$ to $\mathrm{O} 3 . \mathrm{O} 2$ is not involved in any strong hydrogen bond. The carboxylic acid group $\mathrm{C} 8(=\mathrm{O} 3)-\mathrm{O} 4-\mathrm{H} 5$ has a conformation that suggests significant carboxylate character. The $\mathrm{C}-\mathrm{O}$ bond lengths of 1.245 (2) and 1.277 (2) $\AA$ are closer to carboxylate bond lengths, where both $\mathrm{C}-\mathrm{O}$ bonds are expected to be 1.255 (10) $\AA$ (Allen et al., 1992). The $\mathrm{O}-\mathrm{H}$ bond length of 1.311 (5) $\AA$ is extremely long and will be discussed in more detail. This carboxylic acid group participates in two strong hydrogen bonds: $\mathrm{O} 3$ accepts a hydrogen bond from $\mathrm{O} 1$ and $\mathrm{O} 4$ is part of a hydrogen bond to N1. The average $\mathrm{C}-\mathrm{N}-\mathrm{C}$ angle in pyridyl molecules in the CSD (Allen, 2002) is $117.3(2)^{\circ}$, while the average for pyridinium ions is $122.0(2)^{\circ}$. The $\mathrm{C} 2-\mathrm{N} 1-\mathrm{C} 6$ angle of $121.66(13)^{\circ}$ corresponds more closely to the protonated rather than the unprotonated state.

The hydrogen-bond parameters are listed in Table 2. The strong $\mathrm{O} 1-\mathrm{H} 4 \cdots \mathrm{O} 3$ hydrogen bond is an ordered $\mathrm{O}-\mathrm{H} \cdots \mathrm{O}$ bond. The O1 ‥O3 separation of 2.569 (3) $\AA$ is short, but not extremely short, compared with similar hydrogen bonds (Wilson, 2000). The $\mathrm{O}-\mathrm{H}$ and $\mathrm{H} \cdots \mathrm{O}$ distances show no abnormalities compared with $\mathrm{O}-\mathrm{H}$. . O hydrogen bonds of similar length (Steiner \& Saenger, 1994). There is no evidence of disorder in the anisotropic displacement parameters of the proton $\mathrm{H} 4$, which has a $U_{\text {eq }}$ value of $0.0202(8) \AA^{2}$ compared with $0.0190(8), 0.0192(8)$ and $0.0202(8) \AA^{2}$ for the three pyridyl protons, or in the difference Fourier map.

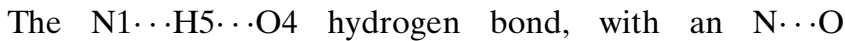
separation of 2.523 (2) $\AA$, is one of the shortest bonds measured by neutron diffraction. As noted above, this hydrogen bond is very similar to the short $\mathrm{N} \cdots \mathrm{H} \cdots \mathrm{O}$ hydrogen bond in BTA.2BPY (Cowan et al., 2003). The N...O separations of $2.523(2) \AA$ in PDA and 2.522 (2) $\AA$ in 2BPY.BTA are essentially identical. This distance lies in the region where the proton position has been found to be near the centre of the hydrogen bond. As in BTA.2BPY, there is no evidence of disorder in the anisotropic displacement para-

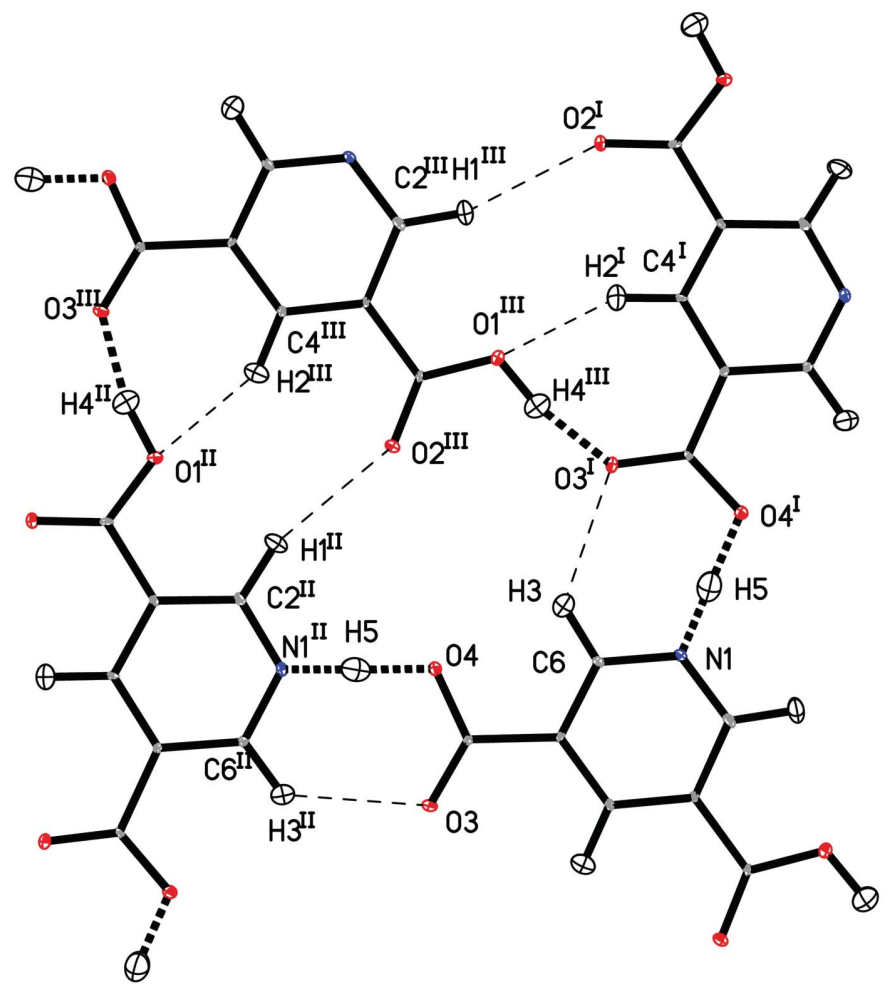

Figure 2

Cooperative intermolecular hydrogen bonding linking the molecules into planar sheets viewed down the $c$ axis. The strong hydrogen bonds are indicated by heavy dashed lines and the weak $\mathrm{C}-\mathrm{H} \cdots \mathrm{O}$ hydrogen bonds are indicated by the thin dashed lines. Symmetry codes: (i) $-x,-\frac{1}{2}+y, \frac{1}{2}-z ;$ (ii) $-1-x, \frac{1}{2}+y, \frac{1}{2}-z$; (iii) $1+x, y, z$. 
meters of the proton $\left[U_{\mathrm{eq}}=0.0220(8) \AA^{2}\right]$ or in the difference Fourier map.

Three weak $\mathrm{C}-\mathrm{H} \cdots \mathrm{O}$ hydrogen bonds are formed in the crystal, two of which directly complement the strong hydrogen bonds. The $\mathrm{C} 6-\mathrm{H} 3 \ldots \mathrm{O} 3$ hydrogen bond parallel to the $\mathrm{N} \cdots \mathrm{H} \cdots \mathrm{O}$ hydrogen bond forms a motif commonly seen in pyridine-carboxylic acid interactions (Shan et al., 2002). The $\mathrm{O}-\mathrm{H} \cdots \mathrm{O}$ hydrogen bond is also complemented by a weak $\mathrm{C}-\mathrm{H} \cdots \mathrm{O}$ hydrogen bond $(\mathrm{C} 4-\mathrm{H} 2 \cdots \mathrm{O} 1)$. The molecules are linked in strongly hydrogen-bonded two-dimensional sheets (Fig. 2). The mean separation between the sheets of molecules is 3.221 (7) $\AA$, corresponding to half of the $c$ axis (Fig. 3). There are no $\pi-\pi$ stacking interactions in this structure. The molecules form a mesh and the symmetry-related molecules in the adjacent planes lie above or below the gaps in the mesh.

Deuterated pyridine-3,5-dicarboxylic acid (d-PDA) was found to be isostructural with PDA at $15 \mathrm{~K}$. Upon refinement of the neutron diffraction data it was discovered that the two carboxylic acid protons had been 92 (1)\% deuterated and that two of the $\mathrm{H}$ atoms attached to the pyridyl ring had become 47 (1)\% deuterated. The occupancies were fixed in the final refinements. The $\mathrm{H}$ atom at position four in the pyridyl ring had not been altered.

There were no significant differences in the intramolecular bond lengths upon deuteration, but the hydrogen bonds did change significantly (Table 2). At $15 \mathrm{~K}$ the $\mathrm{N} \cdots \mathrm{H} \cdots \mathrm{O}$ hydrogen bond lengthened by 0.0154 (3) $\AA$ and the $\mathrm{N}-\mathrm{H}$ distance shortened by 0.063 (5) $\AA$ (the s.u.s were estimated from the measured values as $\sigma^{2}=\sigma_{1}{ }^{2}+\sigma_{2}^{2}$ ), but there were no significant changes in the $\mathrm{O}-\mathrm{H} \cdots \mathrm{O}$ hydrogen bond. There were no differences in the $\mathrm{C}-\mathrm{H}$ bond distances, although the estimated standard deviations were large, especially on the $49 \%$ deuterated $\mathrm{H}$ atoms which have a small net scattering length. Overall the unit-cell volume at $15 \mathrm{~K}$ increased by 1.4 (3) $\AA^{3}$ upon deuteration.

\subsection{Temperature dependence}

The $\mathrm{N}-\mathrm{H} \cdots \mathrm{O}$ hydrogen bond in PDA exhibits almost exactly the same temperature-dependent behaviour as the hydrogen bond in BTA.2BPY. Upon heating to room temperature the $\mathrm{N}-\mathrm{H}$ bond length increases by 0.095 (7) $\AA$ and the $\mathrm{O}-\mathrm{H}$ bond length decreases by 0.093 (8) $\AA$, equivalent to the proton migrating $c a 0.1 \AA$ across the hydrogen bond. As at $20 \mathrm{~K}$, there is no evidence of disorder in the difference Fourier map or the anisotropic displacement parameters of the $\mathrm{H}$ atom (Fig. 4) $\left[U_{\text {eq }}\right.$ for $\mathrm{H} 5$ is 0.0549 (13) $\AA^{2}$ and the $U_{\text {eq }}$ for the three pyridyl $\mathrm{H}$ atoms are 0.0492 (12), $0.0480(13)$ and $0.0540(13) \AA^{2}$ at $\left.296 \mathrm{~K}\right]$. Unlike in BTA.2BPY, the $\mathrm{N} \cdots \mathrm{O}$ distance does not change significantly with temperature. The $\mathrm{O} \cdots \mathrm{O}$ distance of the $\mathrm{O} 1-\mathrm{H} 3 \cdots \mathrm{O} 3$ hydrogen bond in PDA increases by 0.022 (4) $\AA$ on heating to room temperature. As expected, the $\mathrm{O}-\mathrm{H}$ distance increases

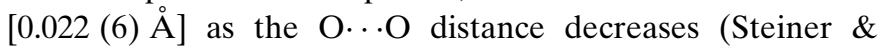
Saenger, 1994) and the $\mathrm{H} \cdots \mathrm{O}$ distance consequently decreases [0.050 (6) $\AA$ ].
In d-PDA the temperature-dependent changes are much more pronounced. On heating to room temperature the $\mathrm{N}-\mathrm{D}$ bond length increases by 0.306 (5) $\AA$ and the $\mathrm{O}-\mathrm{D}$ bond length decreases by 0.280 (5) $\AA$, equivalent to the proton migrating $c a 0.3 \AA$ across the hydrogen bond; at the same time the N1…O 4 distance increases by 0.027 (4) $\AA$. As in PDA there is no evidence of disorder in the difference Fourier map or the anisotropic displacement parameters of the $\mathrm{D}$ atom (Fig. 4). In the $\mathrm{O} 1-\mathrm{D} 4 \cdots \mathrm{O} 3$ hydrogen bond the $\mathrm{O} 1 \cdots \mathrm{O} 3$ distance increases by 0.078 (5) $⿱$ A. The D atom lies slightly closer to the donor $\mathrm{O}$ atom and the decrease in the $\mathrm{O} 1-\mathrm{D} 4$ bond length is similar [0.029 (5) $\AA$ ] to the decrease in $\mathrm{O}-\mathrm{H}$ seen in PDA $[0.022(6) \AA]$. At room temperature the $\mathrm{O}-$ $\mathrm{D}$... O angle is $6.4(4)^{\circ}$ greater than at $15 \mathrm{~K}$.

At $150 \mathrm{~K}$, approximately midway between 15 and $296 \mathrm{~K}$, the hydrogen-bond parameters are all closer to the lowtemperature parameters, which suggests that the changes are not linear with respect to temperature between 15 and $296 \mathrm{~K}$,

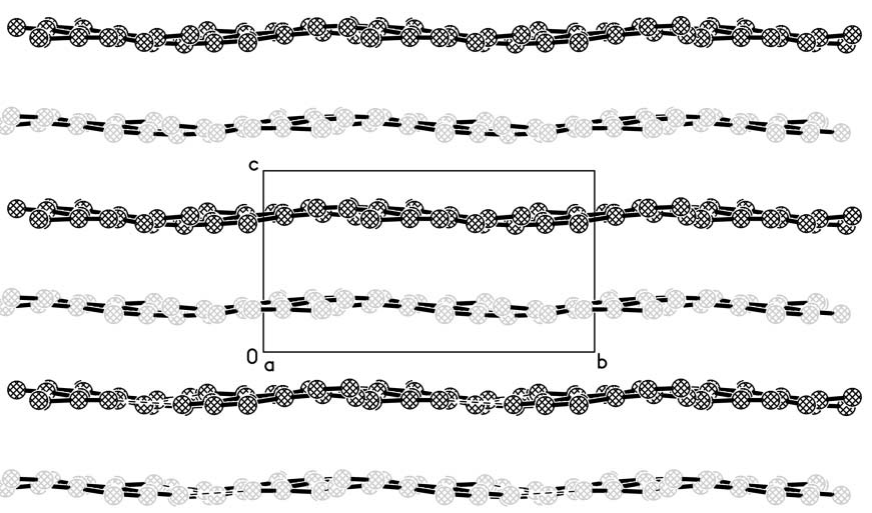

Figure 3

Packing diagram viewed along the $a$ axis. The layers are coloured alternately light and dark grey. There are no strong interactions visible between the molecular layers.

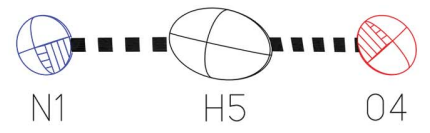

(a) $296 \mathrm{~K}, \mathrm{~N}-\mathrm{H}=1.308(6) \AA$

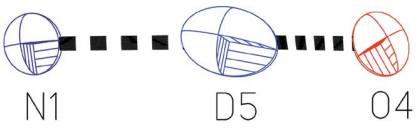

(c) $296 \mathrm{~K}, \mathrm{~N}-\mathrm{D}=1.457$ (4) $\AA$

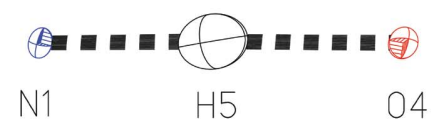

(b) $15 \mathrm{~K}, \mathrm{~N}-\mathrm{H}=1.213(4) \AA$

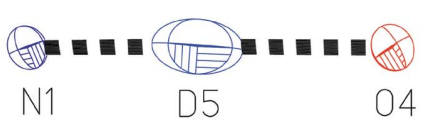

(d) $150 \mathrm{~K}, \mathrm{~N}-\mathrm{D}=1.192(3) \AA$

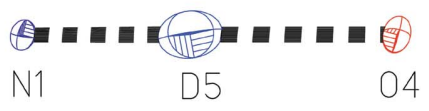

(e) $15 \mathrm{~K}, \mathrm{~N}-\mathrm{D}=1.151(3) \AA$
Figure 4

Displacement ellipsoid plots $(50 \%)$ of the $\mathrm{N}-\mathrm{H}(\mathrm{D})-\mathrm{O}$ hydrogen bond from the neutron data. $(a)$ and $(b)$ are taken from PDA at 296 and $15 \mathrm{~K}$, respectively, and $(c),(d)$ and $(e)$ are taken from d-PDA at 296, 150 and $15 \mathrm{~K}$, respectively. 
and that the main change in the deuterated hydrogen bond occurs above $150 \mathrm{~K}$.

The $\mathrm{N} \cdots \mathrm{H} \cdots \mathrm{O}$ hydrogen bond changes from an approximately $\mathrm{O}-\mathrm{H} \cdots \mathrm{N}$ hydrogen bond, between a carboxylic acid group and a pyridyl group at room temperature, to an approximately $\mathrm{N}-\mathrm{H}^{+} \ldots \mathrm{O}^{-}$hydrogen bond, between a carboxylate and a pyridinium at $15 \mathrm{~K}$. The $\mathrm{C} 8-\mathrm{O} 4$ distance is therefore expected to increase with temperature and the $\mathrm{C} 2-$ $\mathrm{N} 1-\mathrm{C} 6$ angle is expected to decrease. The $\mathrm{C} 8-\mathrm{O} 4$ bond length does not change significantly in PDA, but the pyridyl bond angle changes by $0.7(2)^{\circ}$ from $121.66(13)^{\circ}$ at $15 \mathrm{~K}$ to $120.93(15)^{\circ}$ at room temperature. In d-PDA the changes are more pronounced, the $\mathrm{C} 8-\mathrm{O} 4$ bond length increases by 0.020 (4) $\AA$ from the 1.266 (3) $\AA$ at $15 \mathrm{~K}$ to 1.287 (3) $\AA$ at room temperature, and the pyridyl bond angle decreases by $2.0(2)^{\circ}$ from $121.91(14)^{\circ}$ to $119.88(15)^{\circ}$.

In both PDA and d-PDA the weak $\mathrm{C}-\mathrm{H} \cdots \mathrm{O}$ hydrogen bond lengths also increase with temperature (Table 2). In all but the $\mathrm{C} 6-\mathrm{H} 3 \cdots \mathrm{O} 3$ hydrogen bond the difference is greater in d-PDA than in PDA. The largest change in the cell dimensions with temperature is in the c direction, 0.1470 (14) $\AA$ in PDA and 0.1890 (18) $\AA$ in d-PDA; this is perpendicular to the molecular planes and in the direction along which there are no strong intermolecular interactions. At $15 \mathrm{~K}$ the unit-cell volume of PDA and d-PDA are very similar. The unit-cell volume increases much more in d-PDA than PDA, corresponding to the larger changes in the intermolecular interactions, so that the room temperature unit cell for d-PDA is 12.2 (3) $\AA^{3}$ larger than that of PDA.

\subsection{Proton migration in hydrogen bonds}

In the very similar short $\mathrm{N} \cdots \mathrm{H} \cdots \mathrm{O}$ hydrogen bonds in PDA and BTA.2BPY we have observed the same temperature-dependent behaviour. These hydrogen bonds, along with that between pentachlorophenol and 4-methylpyridine (PCP.4MP, Steiner et al., 2001), which also displays similar

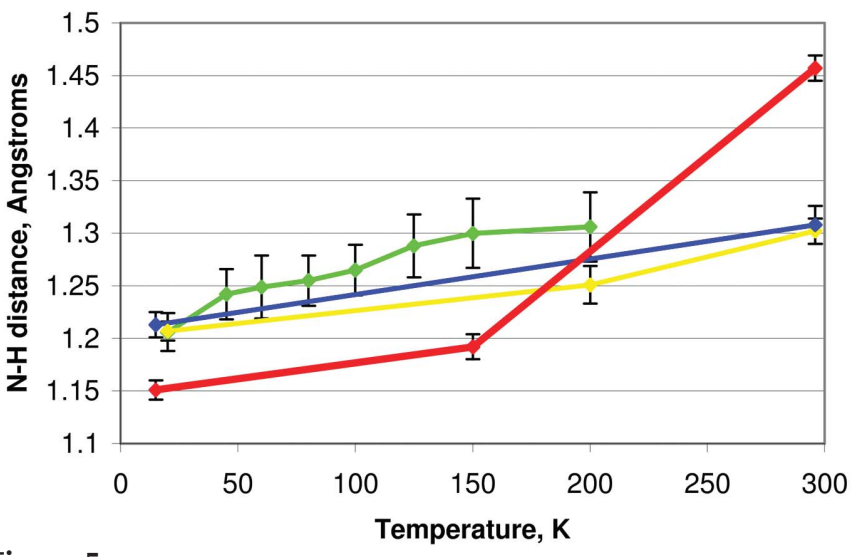

Figure 5

Temperature dependence of the $\mathrm{N}-\mathrm{H}$ distance in short $\mathrm{N} \cdots \mathrm{H} \cdots \mathrm{O}$ hydrogen bonds. PCP.4MP is shown in green, BTA.2BPY in yellow, PDA in blue and d-PDA in red. The lines are meant to associate the points and are not intended to predict the intermediate values. The error bars are at 3 s.u.s. behaviour, are by far the shortest $\mathrm{N} \cdots \mathrm{O}$ hydrogen bonds studied by neutron diffraction.

The magnitude of the H-atom migration is $c a 0.1 \AA$ in PCP.4MP, PDA and BTA.2BPY. The migration takes place below $200 \mathrm{~K}$ in PCP.4MP, with the proton lying equidistant from the nitrogen and the oxygen at $c a 90 \mathrm{~K}$ (Fig. 5). The migration appears to occur over the whole temperature range in BTA-2BPY, although there is only one measurement at an intermediate temperature. There are no intermediate temperature measurements for PDA. The deuterium-atom position in d-PDA changes by $c a 0.3 \AA$ over the temperature range and it appears that the major part of the migration takes place above $150 \mathrm{~K}$.

It is possible that the apparent proton migration in the hydrogen bond is due to disorder. There may be two distinct states in the crystal, one having an $\mathrm{O}-\mathrm{H} \cdots \mathrm{N}$ bond and the other an $\mathrm{N}-\mathrm{H} \cdots \mathrm{O}$ bond, with the structure disordered between the two states and the number of molecules in each state depending on the temperature. The time-averaged $\mathrm{H}$ atom position, measured in diffraction experiments, would appear to move with temperature. This occurs in benzoic acid (Wilson et al., 1996) and is obvious in the $\mathrm{H}$-atom displacement ellipsoids. However, the relevant $\mathrm{H}$-atom displacement ellipsoids in PDA and d-PDA (Fig. 4) show no evidence of disorder, as is also the case in BTA.2BPY and PCP.4MP.

It is also conceivable that a static hydrogen-bond potentialenergy well may be able to explain the observed results for the fully protonated structures. If the potential well has an asymmetric double minimum with a low barrier (Jeffrey, 1997) then at low temperatures the proton will only occupy the lowest possible state in the well, which must lie close to the $\mathrm{N}$ atom. The shape of the potential-energy well may be such that the first excited state may lie closer to the $\mathrm{O}$ atom and as the temperature rises, and this state becomes more populated, the expectation value of the $\mathrm{H}$ atom would move along the hydrogen bond. The potential well must be sufficiently broad so that the first excited state may become populated at thermal temperatures. The stretching frequencies typically observed in hydrogen bonds are of the order $c a 1700-3700 \mathrm{~cm}^{-1}$ (Jeffrey, 1997), corresponding to a temperature of $c a 1100-2500 \mathrm{~K}$. It therefore seems unlikely that the hydrogen-bond potentialenergy well has changed enough to allow the population of the first excited state at temperatures below $300 \mathrm{~K}$. The observed temperature-dependent changes in the $\mathrm{N} \cdots \mathrm{O}$ distances in the fully protonated structures are small and may be due to some uncorrected experimental error. However, the large changes in the $\mathrm{N} \cdots \mathrm{O}$ distance and the changes in the carboxylate and pyridyl groups in d-PDA rule out a static potential-energy well.

The shape of the hydrogen-bond potential-energy well must change due to slight changes in the local environment with temperature, as suggested by Wilson (2001) for the case of urea phosphoric acid, in which proton migration is observed in a short $\mathrm{O} \cdots \mathrm{H} \cdots \mathrm{O}$ hydrogen bond. It must change such that the low-temperature well has its minimum closer to the $\mathrm{N}$ atom and the high-temperature well has its minimum closer to the $\mathrm{O}$ atom. The $\mathrm{N} \cdots \mathrm{O}$ expansion upon deuteration also 
suggests that the potential well is an asymmetric double well at both 15 and 296 K (Singh \& Wood, 1969).

The true situation may be a combination of all these effects. The suggestion of Steiner et al. (2001) that the difference between the structures at room temperature and at $20 \mathrm{~K}$ might be nothing more than an artefact caused by experimental inaccuracies, made after their experiments on PCP.4MP, can, however, be ruled out by the additional experimental evidence in the current work.

\section{References}

Allen, F. H. (2002). Acta Cryst. B58, 380-388.

Allen, F. H., Kennard, O., Watson, D. G., Brammer, L., Orpen, A. G. \& Taylor, R. (1992). International Tables for Crystallography, Vol. C, Table 9.5.1.1, pp. 685-706. Dordrecht: Kluwer Academic Publishers.

Archer, J. M. \& Lehmann, M. S. (1986). J. Appl. Cryst. 19, 456458.

Barthelemy, A., Filhol, A., Rice, P. G., Allibon, J. R. \& Turfat, C. (1984). MAD and HKLGEN. Institut Laue-Langevin, Grenoble, France.

Coppens, P. (1979). Crystallographic Computing, edited by F. R. Ahmed, pp. 255-270. Copenhagen: Munksgaard International Booksellers and Publishers Ltd.

Cowan, J. A., Howard, J. A. K., McIntyre, G. J. M., Lo, S. M.-F. \& Williams, I. D. (2003). Acta Cryst. B59, 794-801.

Filhol, A. (1998). RAFD9. Institut Laue-Langevin, Grenoble, France. Ichikawa, M. (1978). Acta Cryst. B34, 2074-2080.

Jeffrey, G. A. (1997). Introduction to Hydrogen Bonding. Oxford University Press.
Küppers, H., Takusagawa, F. \& Koetzle, T. F. (1985). J. Chem. Phys. 82, 5636-5647.

Nelmes, R. J., Meyer, G. M. \& Tibbalis, J. E. (1982). J. Phys. C, 15, 5975.

Robertson, J. M. \& Ubbelohde, A. R. (1939). Proc. R. Soc. London. Ser. A, 170, 222-240.

Sakhawat Hussain, M. \& Schlemper, E. O. (1980). Acta Cryst. B36, 1104-1108.

Sears, V. F. (1992). Neutron News, 3, 26-37.

Shan, N., Bond, A. D. \& Jones, W. (2002). Cryst. Engng. 5, 9-24.

Sheldrick, G. M. (1990). Acta Cryst. A46, 467-473.

Sheldrick, G. M. (1997). SHELXL97. University of Göttingen, Germany.

Sheldrick, G. M. (1999). SHELXTL/PC, Version 5.10 for Windows NT. Bruker AXS Inc., Madison, Wisconsin, USA.

Singh, T. R. \& Wood, J. L. (1969). J. Chem. Phys. 50, 3572-3576.

Steiner, T., Majerz, I. \& Wilson, C. C. (2001). Angew. Chem. Int. Ed. 40, 2651-2654.

Steiner, T. \& Saenger, W. (1994). Acta Cryst. B50, 348-357.

Takusagawa, F., Hirotsu, K. \& Shimada, S. (1973a). Bull. Chem. Soc. Jpn, 46, 2292-2294.

Takusagawa, F., Hirotsu, K. \& Shimada, S. (1973b). Bull. Chem. Soc. Jpn, 46, 2372-2380.

Takusagawa, F., Hirotsu, K. \& Shimada, S. (1973c). Bull. Chem. Soc. Jpn, 46, 2669-2675.

Takusagawa, F. \& Koetzle, T. F. (1978). Acta Cryst. B34, 1149-1154.

Takusagawa, F. \& Koetzle, T. F. (1979). Acta Cryst. B35, 2126-2135.

Wilkinson, C., Khamis, H. W., Stansfield, R. F. D. \& McIntyre, G. J. (1988). J. Appl. Cryst. 21, 471-478.

Wilson, C. C. (2000). Single Crystal Neutron Diffraction From Molecular Materials. Singapore: World Scientific Publishing.

Wilson, C. C. (2001). Acta Cryst. B57, 435-439.

Wilson, C. C., Shankland, N. \& Florence, A. J. (1996). J. Chem. Soc. Faraday. Trans. 92, 5051-5057. 